\title{
Heat strengthening of double-field coupling demulsification of industrial waste oil emulsion
}

\author{
Ye Peng ${ }^{1,3} \cdot$ Bao Yu ${ }^{2} \cdot$ Xianming Zhang ${ }^{3} \cdot$ Wenlong $\mathrm{Li}^{3} \cdot$ Haifeng Gong ${ }^{3}$
}

Received: 21 July 2018 / Accepted: 21 November 2018 / Published online: 4 December 2018

(c) The Author(s) 2018

\begin{abstract}
Demulsification of highly aqueous waste oil is difficult to complete by a single process efficiently. The dewatering-type hydrocyclone is used as the unit body and includes the high-voltage electrode to realize demulsification and dewatering ability of the coupling of high-voltage electric and swirling centrifugal fields in waste oil emulsion efficiently. This study considers the influence of heating temperature on demulsification in coupled field. Thus, a heat-strengthening double-field demulsification process is proposed. Specifically, the effect of heat strengthening on demulsification, dewatering, and separation of doublefield coupled by numerical simulation and experimental methods was investigated. The temperatures of heat-strengthening were $60{ }^{\circ} \mathrm{C}, 65^{\circ} \mathrm{C}, 70{ }^{\circ} \mathrm{C}$, and $75^{\circ} \mathrm{C}$. The results show that the separation efficiency predicted by numerical simulation are in good agreement with the experimental results. And the heat-strengthening can effectively enhance the separation effect of two fields and improve the efficiency of the oil-water separation of industrial waste oil. When the heating temperature is raised from 60 to $65{ }^{\circ} \mathrm{C}$, and from 65 to $70{ }^{\circ} \mathrm{C}$, the separation efficiency increases by approximately $4.1 \%$ and $6.7 \%$, respectively.
\end{abstract}

Keywords Heat strengthening $\cdot$ Separation $\cdot$ Double-field coupling $\cdot$ Industrial waste oil

\section{List of symbols}

D Nominal diameter, $\mathrm{mm}$

$D_{\mathrm{i}} \quad$ Inlet diameter, $\mathrm{mm}$

$D_{\text {o }} \quad$ Overflow orifice diameter, $\mathrm{mm}$

$D_{\mathrm{u}} \quad$ Underflow orifice diameter, $\mathrm{mm}$

$d \quad$ The initial separation between two dipoles, $\mathrm{m}$

$d_{\mathrm{j}} \quad$ Droplet diameter, $\mathrm{mm}$

$E_{0} \quad$ Amplitude effective value of electric field, $\mathrm{kV} \cdot \mathrm{m}^{-1}$

$E_{i} \quad i=1,2,3$, electric field strength along the axis, $\mathrm{kV} \cdot \mathrm{m}^{-1}$

$E_{j} \quad j=1,2,3$, electric field strength along the axis, $\mathrm{kV} \cdot \mathrm{m}^{-1}$

$E_{S} \quad$ Separation efficiency, \%

$\boldsymbol{F}_{\mathrm{e}} \quad$ Body force, $\mathrm{N}$

Bao Yu

baoyu_1994@163.com

1 School of Mechanical Engineering, Chongqing Technology and Business University, Chongqing 400067, China

2 School of Mechanical Engineering, Chongqing University of Technology, Chongqing 400054, China

3 Engineering Research Centre for Waster Oil Recovery Technology and Equipment of Ministry of Education, Chongqing 400067, China $f_{x}, f_{y}, f_{z} \quad$ Electric field body force along $x, y$, and $z$ direction, $\mathrm{N}$

g Gravitational acceleration, $9.8 \mathrm{~m} \cdot \mathrm{s}^{-2}$

$L_{\mathrm{o}} \quad$ Insertion length of overflow pipe, $\mathrm{mm}$

$L_{\mathrm{u}} \quad$ Length of underflow straight pipe, $\mathrm{mm}$

$n \quad$ Integer $0,1,2 \ldots$

$N \quad$ Number of drops

$p \quad$ Pressure, $\mathrm{Pa}$

$Q_{\text {in }} \quad$ Inlet flow rate, $\mathrm{m}^{3} \cdot \mathrm{h}^{-1}$

$Q_{\text {o }} \quad$ Flow rate of overflow orifice, $\mathrm{m}^{3} \cdot \mathrm{h}^{-1}$

$Q_{\mathrm{u}} \quad$ Flow rate of underflow orifice, $\mathrm{m}^{3} \cdot \mathrm{h}^{-1}$

$r_{1}, r_{2} \quad$ Radius of droplets, $\mathrm{mm}$

$R \quad$ Droplet size, $\mathrm{mm}$

$\boldsymbol{T} \quad$ Maxwell stress tensor

$T_{i j} \quad$ Element of Maxwell stress tensor

$t \quad$ Residence time, $\mathrm{s}$

$t_{1} \quad$ Coalescence time of two drops, $\mathrm{s}$

$v_{\mathrm{dr}, \mathrm{k}} \quad$ Drift velocity of phase $\mathrm{k}, \mathrm{m} \cdot \mathrm{s}^{-1}$

$v_{\mathrm{k}} \quad$ Velocity of phase $\mathrm{k}, \mathrm{m} \cdot \mathrm{s}^{-1}$

$v_{\mathrm{m}} \quad$ Velocity of the mixture phase, $\mathrm{m} \cdot \mathrm{s}^{-1}$

$V_{x y z} \quad$ Volume of cell, $\mathrm{m}^{3}$

$\alpha \quad$ Large cone angle, ${ }^{\circ}$

$\alpha_{\mathrm{k}} \quad$ Volume fraction of phase k, $\%$

$\alpha_{\text {in }} \quad$ Volume fraction of inlet orifice

$\alpha_{\mathrm{o}} \quad$ Volume fraction of overflow orifice 


$\begin{array}{ll}\alpha_{\mathrm{u}} & \text { Volume fraction of underflow orifice } \\ \beta & \text { Small cone angle, } \\ \delta_{i j} & \text { Kronecker delta } \\ \varepsilon_{0} & \text { Permittivity of vacuum, } \mathrm{F}^{-1} \mathrm{~m}^{-1} \\ \varepsilon_{\mathrm{r}} & \text { Relative permittivity of oil } \\ \theta & \text { Angle between the line joining the centers of } \\ & \text { droplets with direction of electric field } \\ \mu_{\mathrm{k}} & \text { Viscosity of phase } \mathrm{k}, \mathrm{Pa} \cdot \mathrm{s} \\ \mu_{\mathrm{m}} & \text { Viscosity of mixture phase, } \mathrm{Pa} \cdot \mathrm{s} \\ \mu_{\mathrm{o}} & \text { Viscosity of oil phase, } \mathrm{mPa} \cdot \mathrm{s} \\ \mu_{\mathrm{w}} & \text { Viscosity of water phase, } \mathrm{mPa} \cdot \mathrm{s} \\ \rho_{\mathrm{k}} & \text { Density of phase } \mathrm{k}, \mathrm{kg} \cdot \mathrm{m}^{-3} \\ \rho_{\mathrm{m}} & \text { Mixture density, } \mathrm{kg} \cdot \mathrm{m}^{-3} \\ \rho_{\mathrm{o}} & \text { Oil phase density, } \mathrm{kg} \cdot \mathrm{m}^{-3} \\ \rho_{\mathrm{w}} & \text { Water phase density, } \mathrm{kg} \cdot \mathrm{m}^{-3} \\ \tau & \text { Shear stress tensor, } \mathrm{Pa} \\ \varphi & \text { Water volume fraction in oil, } \%\end{array}$

\section{Introduction}

The beneficial reuse of industrial waste oil is important to alleviate energy shortage and improve environmental protection. The first key link of reuse is the demulsification of the waste oil emulsion [1-3]. In general, demulsification of water-in-oil emulsion is difficult to achieve by a single process efficiently. Demulsification technologies usually couple and integrate two and more processes or units to complete the separation process; thus, they are difficult to adapt to the conventional process [4-6]. For the W/O industrial waste oil of high water content and complex components, the dewatering-type hydrocyclone can be used as the body and the high-voltage electrode is embedded to generate and couple high-voltage electric and swirling centrifugal fields for realizing the efficient separation and treatment of the waste oil emulsion [7].

At present, there are several studies that the demulsification of water-in-oil emulsion is achieved by coupling the electric and centrifugal fields [8]. Bailes et al. [9] used a combination of high-voltage DC electric and centrifugal fields to complete the demulsification of crude oil. The results confirmed that the demulsification efficiency of the combination of electric and centrifugal fields is better than that of the combination of electric and gravity fields. Similarly, Eow et al. [10,11] performed a centrifugal electrocoalescer-separator, studied the separation efficiency by experimental methods, and found that the maximum separation efficiency was about 93\%. Yang et al. [12] mainly studied the problem of droplet deformation and optimal demulsification frequency under the combination of centrifugal and pulsed electric fields. Wang and Sun et al. [13, 14] explored the influence of swirling field structure on the separation of water-in-oil emulsion under the combination of centrifugal and pulsed electric fields. Li et al. [15] conducted an experiment of water separation from W/O emulsion by a new equipment which coupled electric and centrifugal fields, investigated the influence of electric field frequency and voltage on the water separation efficiency and achieved the optimal operation parameters. In the double-field coupling demulsification technology, two important processes are integrated: the electric field demulsification and the swirling centrifugal separation [16-19].

In electric field demulsification, one of the key factors affecting the efficiency of demulsification is the electric field strength [15, 20-22]. In the double-field coupling demulsification process, the electric field increases the concentration of small droplets in the water-in-oil emulsion, and the appropriate electric field strength can achieve a reasonable size of droplet of water-in-oil emulsion effectively. As a result, the centrifugal force in the swirling field is high and the efficiency of oil-water separation is improved [22]. The inlet velocity of the fluid in the swirling flow field is also important for oil-water separation [23]. In addition, the emulsion properties also influence the separation process, such as the density difference, water volume fraction, interfacial tension, and the oil viscosity [24-26]. The oil viscosity can be affected by changing the oil temperature [27].

In this study, the influence of oil viscosity on the centrifugal separation of water-in-oil emulsion droplets is considered. Thus, a heat-strengthening double-field demulsification process is proposed to enhance the separation effect of double-field coupling unit. And the effect of heat-strengthening on the improvement in the demulsification efficiency of double-field coupling unit is investigated by numerical simulation and experimental methods.

\section{Mechanisms and process}

\section{Mechanisms of separation}

When electric field is applied in emulsion, the coalescence of dispersion droplets in oil occurs, resulting in the size of droplets increasing constantly [28]. Under the action of electric field, the coalescence between droplets occurs in three stages: droplets approaching each other, film thinning and film rupture [29]. For two spherical droplets with the radius of $r_{1}$ and $r_{2}$, the electric field force of radial $\left(F_{\mathrm{r}}\right)$ and angular $\left(F_{\theta}\right)$ directions can be expressed as [15]:

$$
\begin{aligned}
& F_{\mathrm{r}}=\frac{-12 \pi \varepsilon_{0} \varepsilon_{\mathrm{r}} r_{1}^{2} r_{2}^{2} E_{0}^{2}}{\left(d+r_{1}+r_{2}\right)^{4}}\left(3 \cos ^{2} \theta-1\right) \\
& F_{\theta}=\frac{-12 \pi \varepsilon_{0} \varepsilon_{\mathrm{r}} r_{1}^{2} r_{2}^{2} E_{0}^{2}}{\left(d+r_{1}+r_{2}\right)^{4}} \sin 2 \theta
\end{aligned}
$$


where $E_{0}$ is the applied electric field strength, and $d$ and $\theta$ are the initial separation between two dipoles and the angle between the line joining the centers of droplets with applied direction of applied electric field, respectively.

For the droplets with the same radius $\left(r_{1}=r_{2}\right)$ and $\theta$ is zero, the electric field force can be written as [15]:

$F_{\mathrm{e}}=\frac{-24 \pi \varepsilon_{0} \varepsilon_{\mathrm{r}} r_{1}^{2} r_{2}^{2} E_{0}^{2}}{\left(d+r_{1}+r_{2}\right)^{4}}$

In this case, the force $F_{\mathrm{e}}$ is proportional to $E_{0}^{2}$. And increasing the electric field strength can effectively improve the coalescence of water droplets in oil to enlarge the size of droplets.

For the emulsion with large size of droplets, the centrifugation method can be used for separating water from oil effectively. The separation of oil and water by centrifugal is based on the density difference [30]. Due to the centrifugal forces, the water droplets with higher density than the oil move to the region far from the axis of rotating [31]. And the larger density difference is, the dispersion phase separated from the oil is more easily. For example, in liquid-liquid hydrocyclone, the density difference is proportional to the separation efficiency of hydrocyclone, and the larger the density difference, the greater the centrifugal field strength [32]. In addition, the centrifugal sedimentation velocity is also proportional to the density difference. The relation between the he centrifugal sedimentation velocity and density difference can be described [19]:

$v_{\mathrm{s}}=a \frac{d_{j}^{2} \Delta \rho}{18 \mu_{\mathrm{m}}}$

where the $v_{\mathrm{s}}$ is the centrifugal sedimentation velocity of the droplets, $\Delta \rho$ is the density difference, $a$ and $\mu_{\mathrm{m}}$ are the acceleration of the droplets and dynamic viscosity of the emulsion, respectively.

Therefore, by coupling electric and centrifugal fields, the size of the droplets enlarges and separates from the oil quickly and effectively in a short time, improving the separation efficiency of oil and water. For instance, Eow et al. [11] developed a centrifugal electrocoalescer separator that uses combined electrical and centrifugal effects, studied the effect of applied pulsing frequency on the separation efficiency, and found that the separation efficiency can up to $93 \%$ when the applied potential, pulsing frequency and inlet drop diameter are $4 \mathrm{kV}, 100 \mathrm{~Hz}$, and $1.15 \mathrm{~mm}$. Their work demonstrated that separating the water droplets from the oil by coupling electric and centrifugal fields is feasibility.

\section{Heat-strengthening separation process}

As shown in Fig. 1, the water-in-oil emulsion is pumped into the heating tank. The heating tank has a heating control system that can increase the oil temperature to a set value in a relatively short period. Heating can effectively reduce the viscosity of the oil. Through the screw pump, the water-in-oil emulsion quickly enters the double-field coupling demulsification unit at a set flow rate, and the heat-strengthening separation treatment of water-in-oil emulsion is realized. By the coupling unit, water in the oil can be separated from the emulsion and flows into the underflow tank, and the oil with little water flows into the overflow tank.

\section{Numerical models and calculations}

\section{Numerical model}

The high-voltage electrode electric field is embedded in a swirl chamber segment and uses a dewatering-type double cone hydrocyclone as the main structure. The application of a high-voltage electric field completes the coalescence of small emulsion droplets in a short time. The sedimentation and separation of coalesced droplets can be realized in a short time in the swirling centrifugal field. The demulsification efficiency of the water-in-oil emulsion can be improved as a whole. The efficient and rapid dewatering of the waste oil can be realized [33]. The geometric model of the coupling unit of the swirling centrifugal and high-voltage electric fields is established and shown in Fig. 2. A high-voltage electric field is formed between the cylindrical outer surface of the overflow orifice section and the corresponding cylinder surface of the swirl chamber section.

In this work, the liquid-liquid two-phase flow in a doublefield coupled unit was simulated transiently by Mixture model. The oil-water mixture fluid satisfies the following governing equations of continuity and Navier-Stokes $(\mathrm{N}-\mathrm{S})$ equations.

$\frac{\partial \rho_{\mathrm{m}}}{\partial t}+\nabla \cdot\left(\rho_{\mathrm{m}} v_{\mathrm{m}}\right)=0$,

where $\rho_{\mathrm{m}}=\sum_{k=1}^{n} \alpha_{k} \rho_{k}$ and $v_{\mathrm{m}}=\sum_{k=1}^{n} \alpha_{k} \rho_{k} v_{k} / \rho_{\mathrm{m}}$.

$$
\begin{gathered}
\frac{\partial}{\partial t}\left(\rho_{\mathrm{m}} v_{\mathrm{m}}\right)+\nabla \cdot\left(\rho_{\mathrm{m}} v_{\mathrm{m}}^{2}\right)=-\nabla p+\nabla \cdot \tau \\
+\rho_{\mathrm{m}} g+F_{e}+\nabla \cdot\left(\sum_{k=1}^{n} \alpha_{k} \rho_{k} v_{\mathrm{dr}, \mathrm{k}}^{2}\right),
\end{gathered}
$$

where $\tau=\mu_{\mathrm{m}}\left[\nabla v_{\mathrm{m}}+\left(\nabla v_{\mathrm{m}}\right)^{T}\right], \quad \mu_{\mathrm{m}}=\sum_{k=1}^{n} \alpha_{k} \mu_{k}, \quad$ and $v_{\mathrm{dr}, \mathrm{k}}=v_{\mathrm{k}}-v_{\mathrm{m}}$ 
Fig. 1 Heat-strengthening double-field demulsification process

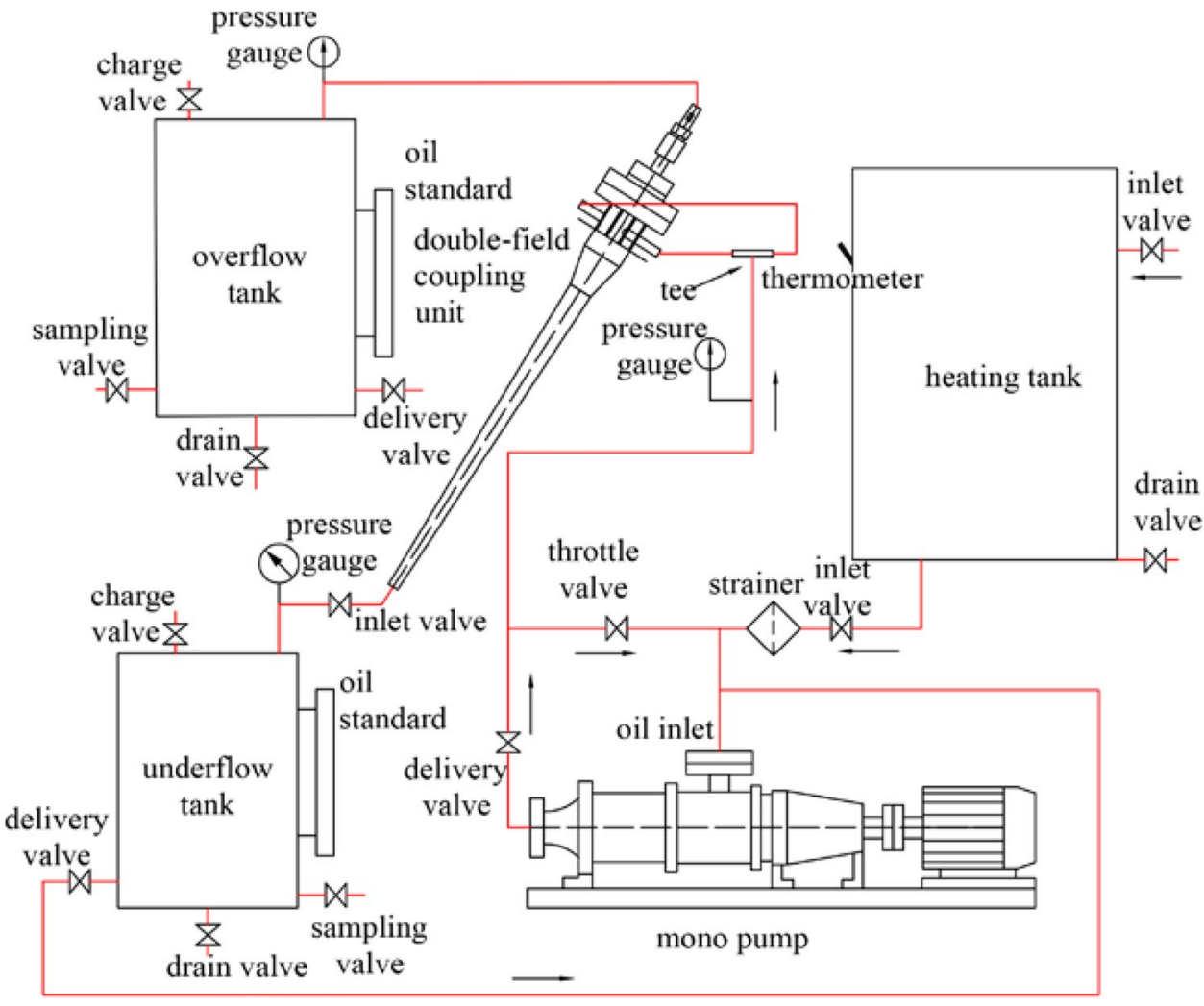

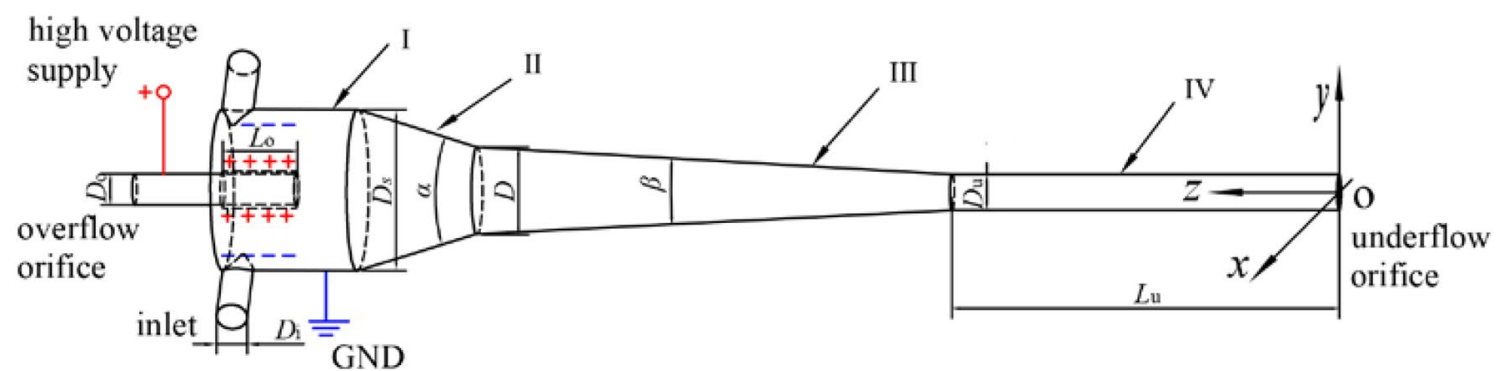

Fig. 2 Geometry model of double-field coupling unit, including I: the swirl chamber section, II: large cone section, III: small section, and IV: the straight pipe section $\left(D=26 \mathrm{~mm}, D_{\mathrm{i}}=12 \mathrm{~mm}, D_{\mathrm{o}}=18 \mathrm{~mm}, L_{\mathrm{o}}=45 \mathrm{~mm}, \alpha=20^{\circ}, \beta=3^{\circ}, D_{\mathrm{u}}=10 \mathrm{~mm}\right.$, and $\left.L_{\mathrm{u}}=400 \mathrm{~mm}\right)$

Considering the anisotropy of flow in the coupling unit, the rotating turbulent flow is described by the Reynolds Stress Model (RSM) turbulence model.

In addition, the action of the electric field is considered. Under the action of electric field, the electric field force of droplets can be expressed by Maxwell stress tensor in the physical model of double-field coupling unit [34].

$T_{i j}=\varepsilon_{0} \varepsilon_{\mathrm{r}}\left(E_{i} E_{j}-\frac{1}{2} \delta_{i j} E_{0}^{2}\right)$

where $T_{i j}$ is the element of Maxwell stress tensor and $\delta_{i j}$ is the Kronecker delta.
The volume force of the electric field is added as an external volume force to the $\mathrm{N}-\mathrm{S}$ equation. The physical model of the double-field coupling unit uses the Descartes coordinate system. Thus, the electric field force can be expressed as the volume force component, $f_{x}, f_{y}, f_{z}$, of three electric fields.

$\boldsymbol{F}_{\mathrm{e}}=\left(f_{x}, f_{y}, f_{z}\right)=\nabla \cdot \boldsymbol{T}$

Under the action of electric field, the size of the droplets changes. In accordance with the Atten droplet pairing model [35], when $N$ droplets with radius $R$ are aggregated into $0.5 \mathrm{~N}$ droplets with radius $2^{1 / 3} R$, the coalescence time can be calculated by the following Stokes formula: 
$t_{1}=\frac{8}{15} \frac{\mu_{o}}{\varepsilon_{\mathrm{r}} \varepsilon_{0} E_{0}^{2}}\left[\left(\frac{\pi}{6 \varphi}\right)^{5 / 3}-1\right]$

where $\mu_{\mathrm{o}}$ and $\varphi$ are the viscosity of oil phase and water volume fraction in oil, respectively.

Therefore, when the residence time $t$ of the droplet in the electric field zone is calculated and the coalescence time is obtained by Eq. (9), the size of the droplets is $\left(2^{n}\right)^{1 / 3} R$ where $n$ is the ratio of $t$ to $t_{1}$ is determined and rounded off.

\section{Flow field and boundary conditions}

This study uses $20^{\#}$ oil (the viscosity grade is 20) as continuous phase, water as dispersed phase, and $200 \mu \mathrm{m}$ as droplet diameter. The oil is heated at $60^{\circ} \mathrm{C}, 65^{\circ} \mathrm{C}, 70^{\circ} \mathrm{C}$, and $75^{\circ} \mathrm{C}$, and the underflow split ratio, which is defined as the ratio of the underflow rate to the total inlet flow rate, is set to $10 \%$. Table 1 shows the related parameters of the flow field.

The entrance boundary is used as the velocity entrance, and the entrance section normal velocity is $10 \mathrm{~m} / \mathrm{s}$. The two other direction speeds are 0 , the water content in the emulsion is $10 \%$, the inlet turbulence intensity is $5 \%$, and the entrance diameter is $12 \mathrm{~mm}$. The export boundary is outflow that is a free export. The wall surface is under a no-slip boundary condition, and the standard wall function is used to process the near wall area. The unidirectional DC electric field voltage amplitude is $11 \mathrm{kV}$. The overflow pipe extends into the wall surface of the segment as the high-voltage input terminal of the electric field, and the inner wall surface of the swirl chamber acts as the ground of the electric field.

In this study, the Fluent (ANSYS 15.0) is used for the numerical simulation. A user-defined function method is used to establish the potential equation of the physical model of the multi-field coupling unit. The electric field strength is solved by the Maxwell stress tensor method based on the aforementioned equation. The electric field force can be calculated and the volume force is added to the $\mathrm{N}-\mathrm{S}$ equation as the source term $[36,37]$. The finite volume method is used to control the equation and the time step is $0.05 \mathrm{~s}$.

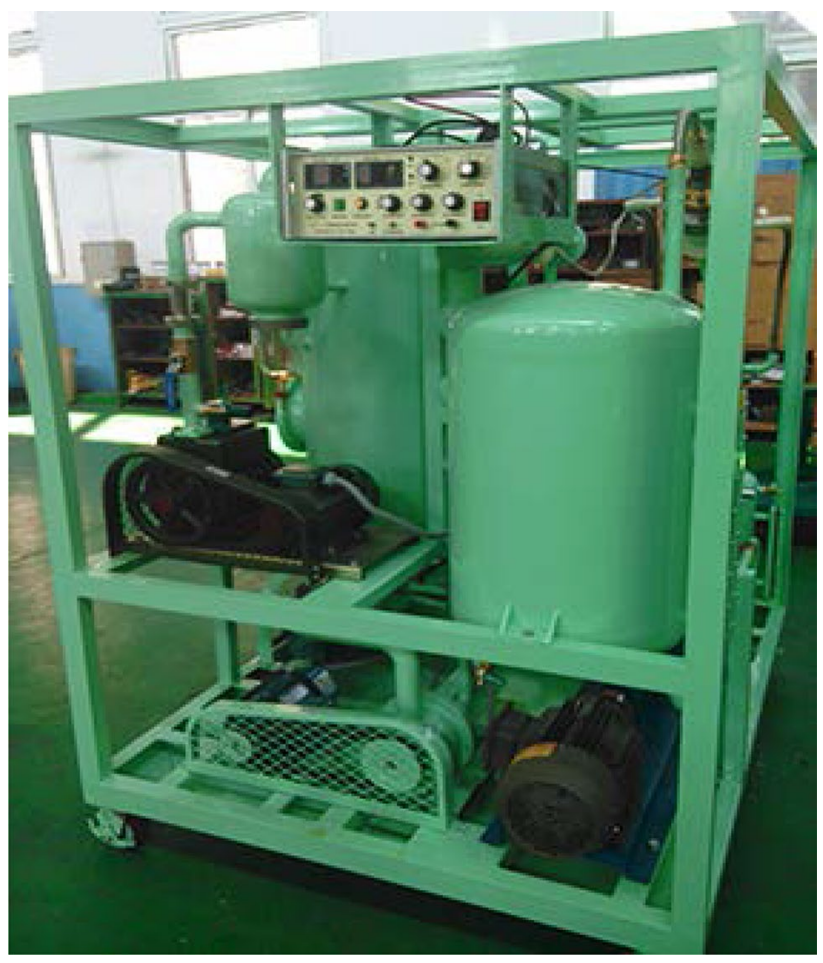

Fig. 3 The experimental setup for conducting the demulsification experiment of $\mathrm{W} / \mathrm{O}$ emulsion

\section{Experimental methods}

The experimental setup used to conduct the demulsification experiment of $\mathrm{W} / \mathrm{O}$ emulsion is shown in Fig. 3. The setup mainly includes a high-voltage source, single-screw pump, two-field coupling unit, overflow tank, underflow tank, and heating tank. The output voltage, frequency, and duty ratio of the high-voltage source (HD15-1.0), supported by Tianjin Huida co., can be adjusted, and the values are within 0-20 kV, 0.1-5000 Hz, and 30-60\%. The single-screw pump (G35-1), supported by Shanghai An Huai Pump co., Ltd., can provide the steady flow, avoiding the further emulsification and shearing actions of the emulsion samples. And the geometry structure and the corresponding parameters of two-field coupling unit are shown in Fig. 2. The volume of the overflow tank is $70 \mathrm{~L}$ and the volume of the underflow tank is $23 \mathrm{~L}$. In addition, the heating tank can be used to heat $100 \mathrm{~L}$ emulsion. In addition, some valves are also applied in the setup. By adjusting the inlet and delivery valves, the

Table 1 Parameters of flow field

\begin{tabular}{llllllll}
\hline$Q_{\text {in }}\left(\mathrm{m}^{3} \mathrm{~h}^{-1}\right)$ & $\rho_{\mathrm{w}}\left(\mathrm{kg} \mathrm{m}^{-3}\right)$ & $\rho_{\mathrm{o}}\left(\mathrm{kg} \mathrm{m}^{-3}\right)$ & $\mu_{\mathrm{w}}(\mathrm{mPa} \mathrm{s})$ & $\mu_{0(60)}(\mathrm{mPa} \mathrm{s})$ & $\mu_{0(65)}(\mathrm{mPa} \mathrm{s})$ & $\mu_{0(70)}(\mathrm{mPa} \mathrm{s})$ & $\mu_{0(75)}(\mathrm{mPa} \mathrm{s})$ \\
\hline 4.0 & 998.3 & 863.0 & 1.3 & 24.6 & 20.1 & 16.8 & 14.2 \\
\hline
\end{tabular}


underflow split ratio can be controlled. The oil samples used to measure the water content can be collected at the sampling valves and the separation efficiency of the setup can be obtained.

In the experiment, the oil selected the continuous phase and the water, dispersed in the oil, was selected as the dispersed phase. A kinematic viscosity tester (BF-03) was used to measure the kinematic viscosity of the oil and water samples at the room temperature. At the same time, a density tester (BF-18A) was used to measure the density. The corresponding physical parameters are shown in Table 1 . The W/O emulsion was prepared by mixing the oil and water samples using a power basic stirrer (MGD699). The volume fraction of water was $10 \%$. To keep the stability of the emulsion, $5 \mathrm{~g} / \mathrm{L}$ of Span- 80 was added as a surfactant. The split ratio of under orifice was specified as 0.1 . The unidirectional DC electric field voltage amplitude was specified to $11 \mathrm{kV}$. Additionally, a trace moisture tester (SYD-2122C) was used to measure the water content of oil samples. The experiment was repeated at different temperatures $\left(60^{\circ} \mathrm{C}, 65^{\circ} \mathrm{C}, 70^{\circ} \mathrm{C}\right.$, and $75^{\circ} \mathrm{C}$ ). The experimental results were calculated from an average of three experiments for each specific temperature: $60{ }^{\circ} \mathrm{C}, 65^{\circ} \mathrm{C}, 70{ }^{\circ} \mathrm{C}$, and $75^{\circ} \mathrm{C}$.
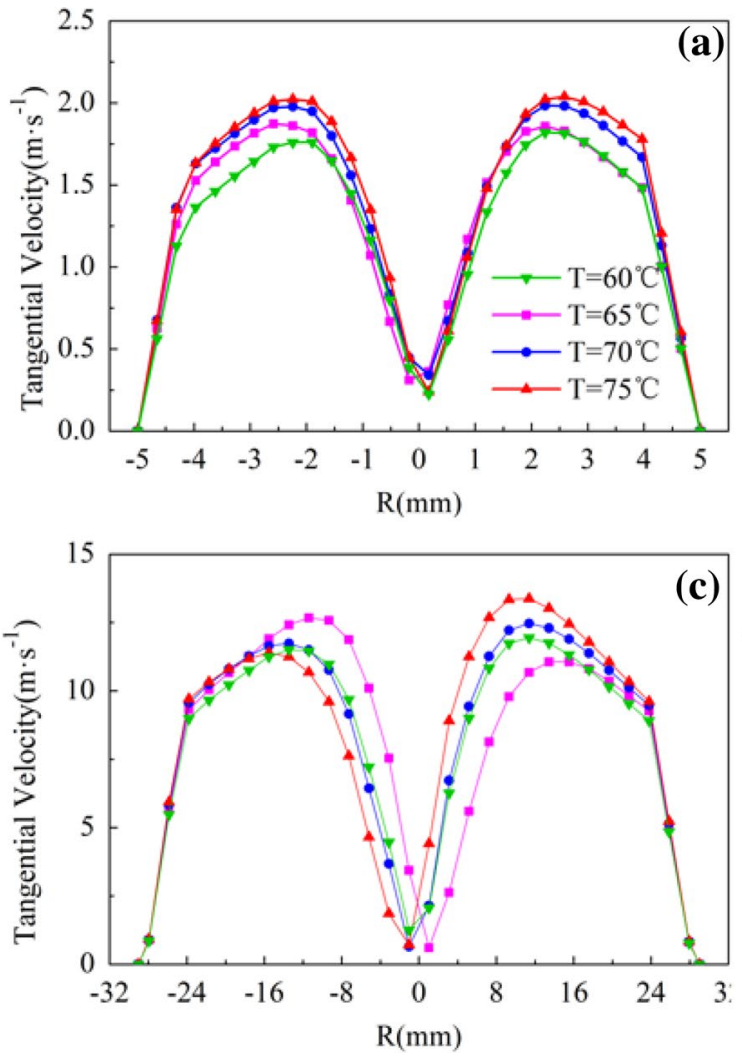

Fig. 4 The radial distribution of tangential velocity profiles for different emulsion temperatures at four different sections: $\mathbf{a} z=100 \mathrm{~mm}$; b $z=620 \mathrm{~mm} ; \mathbf{c} z=750 \mathrm{~mm}$; d $z=790 \mathrm{~mm}$. Green line + symbol:

\section{Results and discussion}

\section{Effect of heating temperature on flow field}

The fluid movement characteristics of the inner coupling unit at $60{ }^{\circ} \mathrm{C}, 65^{\circ} \mathrm{C}, 70{ }^{\circ} \mathrm{C}$, and $75^{\circ} \mathrm{C}$ are studied in the underflow straight pipe section $(z=100 \mathrm{~mm})$, small cone section $(z=620 \mathrm{~mm})$, large cone section $(z=750 \mathrm{~mm})$, and swirling chamber section $(z=790 \mathrm{~mm})$ on the $x=0$ cross section. Separation efficiency is an important indicator for evaluating a separation device, such as a liquid/liquid hydrocyclone. The separation efficiency is the ratio of the flow rate of overflow to the flow rate of inlet and is defined as follows [38]:

$E_{\mathrm{S}}=\frac{\alpha_{\mathrm{o}} Q_{\mathrm{o}}}{\alpha_{\mathrm{in}} Q_{\mathrm{in}}}=1-\frac{\alpha_{\mathrm{u}} Q_{\mathrm{u}}}{\alpha_{\text {in }} Q_{\text {in }}}$

In the double-field coupling unit, discretely distributed water droplets move toward the side wall under the action of centrifugal force to separate the oil-water two-phase flow. The separation efficiency of the device is directly related to the tangential velocity of the water droplets,
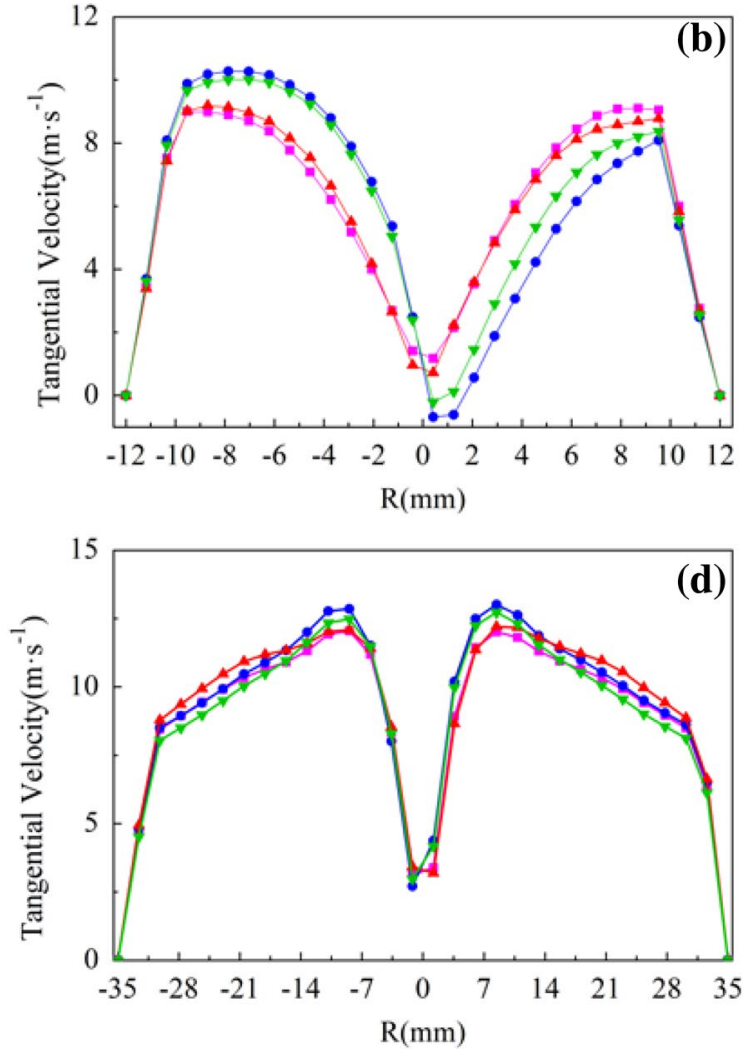

$60{ }^{\circ} \mathrm{C}$, magenta line + symbol: $65^{\circ} \mathrm{c}$, blue line + symbol: $70{ }^{\circ} \mathrm{c}$, red line + symbol: $75^{\circ} \mathrm{C}$ 
which dominates the three velocity components. Figure 4 shows the distribution of tangential velocity curves on four cross sections. The figure shows that, when the temperature changes, the tangential speeds change considerably. In particular, in the $z=100 \mathrm{~mm}$ section, the tangential velocity increases when the temperature increases from 60 to $75{ }^{\circ} \mathrm{C}$. Therefore, as the temperature of the water-in-oil emulsion rises, the distribution of the internal speed of the coupling unit changes, which can improve the separation efficiency of the emulsion. The reason is that the centrifugal force, which promotes the separation of the oil-water two-phase flow, is exerted on the droplets of the dispersed phase in the water-in-oil emulsion and increases with the increase of tangential velocity, thereby improving the separation efficiency. The tangential velocity on the section of the cone changes remarkably with no obvious increasing or decreasing trend. In particular, when the temperature is $60{ }^{\circ} \mathrm{C}$ or $70^{\circ} \mathrm{C}$, the tangential velocity in the small cone shows no obvious M-type symmetry. This velocity is much larger than that at the two other temperatures in the $R<0$ area, and the opposite result is found in the $R>0$ area. This phenomenon indicates that the flow in the cone is unstable and the tangential velocity is greatly affected by the temperature. In the $z=790 \mathrm{~mm}$ section, the tangential velocity increases slightly from 60 to $75^{\circ} \mathrm{C}$ except in the peak area. In the peak area, the maximum speed at $70{ }^{\circ} \mathrm{C}$ is higher than the maximum speed at the other temperatures. The variation in tangential velocity occurs in the inner and outer vortex area except in the vicinity of the wall surface. The reason is that the no-slip boundary condition was applied.

\section{Effect of heating-strengthening temperature on separation}

Figure 5a shows the contour of oil volume fraction on $x=0$ and $0<z<925 \mathrm{~mm}$ at different temperatures. The figure shows that, as the temperature increases, the fluid area with oil volume fraction higher than 0.95 is concentrated in the swirl chamber and the large cone section. In particular, when the temperature rises from 60 to $65{ }^{\circ} \mathrm{C}$, or from 65 to $70{ }^{\circ} \mathrm{C}$, the range of high oil concentration changes obviously, and the oil volume fraction of the bottom is reduced by 0.05 . When the temperature rises further to $75^{\circ} \mathrm{C}$, the oil volume fraction distribution does not change considerably. Therefore, the effect of oil-water separation is obvious when the temperature is raised from 60 to $70{ }^{\circ} \mathrm{C}$, or from 65 to $70{ }^{\circ} \mathrm{C}$, the separation efficiency of the coupling unit is obviously improved. However, the increase in temperature will not continuously improve the water separated from emulsion oil. Thus, the effect of the separation efficiency is also weakened. Figure $5 \mathrm{~b}$ shows the distribution of oil concentration in $x=0$ and $730 \mathrm{~mm}<z<840 \mathrm{~mm}$ section. The figure shows that, when the temperature rises, the area of oil volume fraction higher than $95 \%$ increases. When the temperature rises from 60 to $70{ }^{\circ} \mathrm{C}$, or from 65 to $70{ }^{\circ} \mathrm{C}$, the change in high oil concentration range is most obvious. This finding indicates that the increase in temperature is beneficial to the gathering of oil to the area near the overflow orifice. As a result, the water content of the oil discharged through the overflow is low and the dewatering efficiency of the overflow is improved. However, the distribution of the oil concentration will not change considerably when the temperature rises further to $75{ }^{\circ} \mathrm{C}$ and the separation efficiency will not be greatly improved owing to the limit of the

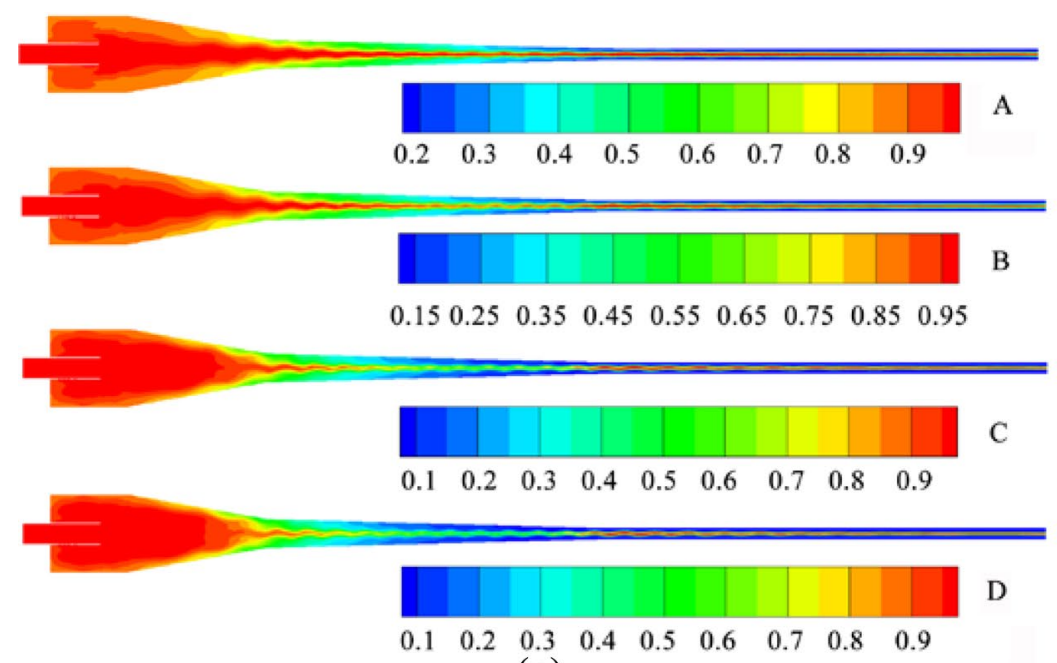
(a)

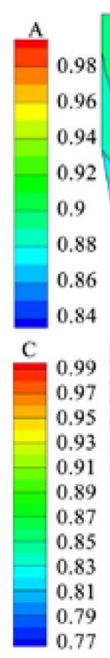

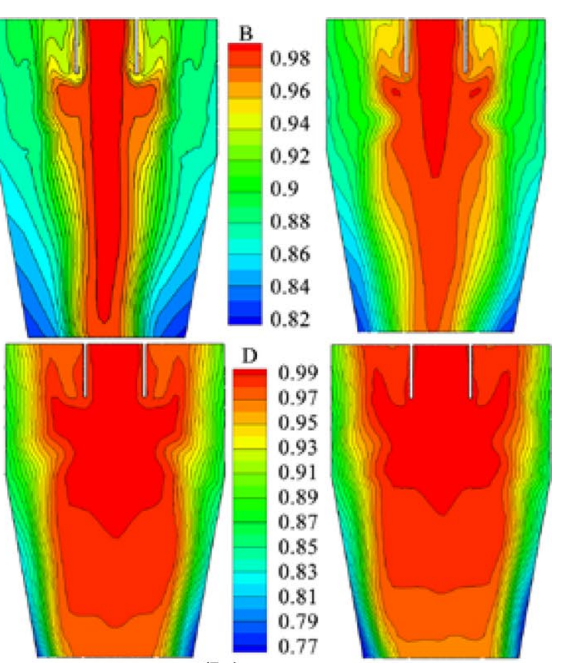

(b)

Fig. 5 The contour of oil volume fraction for four different emulsion temperatures $\left(\mathrm{A}: 60{ }^{\circ} \mathrm{C}, \mathrm{B}: 65^{\circ} \mathrm{C}, \mathrm{C}: 70{ }^{\circ} \mathrm{C}\right.$, and $\left.\mathrm{D}: 75{ }^{\circ} \mathrm{C}\right)$ : $\mathbf{a}$ at $x=0$, $0<z<925 \mathrm{~mm}$ of double-field coupling unit; $\mathbf{b}$ at $x=0$ and $730 \mathrm{~mm}<z<840 \mathrm{~mm}$ 
structural parameters of the overflow orifice. When the temperature is $60^{\circ} \mathrm{C}$ or $65^{\circ} \mathrm{C}$, the oil concentration equivalents are thinning with the oil concentration less than $95 \%$, and the concentration equivalents become homogeneous and dense when the temperature rises to $70^{\circ} \mathrm{C}$ or $75^{\circ} \mathrm{C}$. Therefore, the increase in temperature will promote the oil-water separation process, and the effect of liquid flow on the distribution of oil concentration in the junction area between the swirl chamber and the large cone section is small.

Figure 6 shows the distribution of the oil volume near the underflow and overflow orifices under different temperature conditions. Figure $6 \mathrm{a}$ shows that, as the temperature rises, the oil concentration gradually decreases. It indicates that, as the temperature increases, the separation of the oil-water two-phase flow within the coupling device is promoted. As a result, the water flow rate of the liquid flow discharged through the underflow orifice is increased, and the oil-water separation is improved. When the temperature rises from 65 to $70{ }^{\circ} \mathrm{C}$, the degree of separation promotion is high. Figure $6 \mathrm{~b}$ shows that, when the temperature rises, the volume fraction of oil gradually increases and the range of high oil volume is wide. Therefore, the increase in temperature expands the area of high oil concentration in the area near the overflow orifice, that is, the increase in temperature effectively improves the separation efficiency. When the temperature increases from 70 to $75^{\circ} \mathrm{C}$, the oil volume fraction in the $-15 \mathrm{~mm}<R<15 \mathrm{~mm}$ range unremarkably changes. This finding shows that, when the temperature is $70^{\circ} \mathrm{C}$, the separation of oil-water in the junction area between the swirl chamber and the cone section is already sufficient. The continuous increase in temperature will inconsiderably increase the separation efficiency. Overall, the increase in temperature can improve the oil-water separation efficiency of the coupling unit.

The separation efficiency calculated from experimental results was obtained using the Eq. (5). Similarly, for

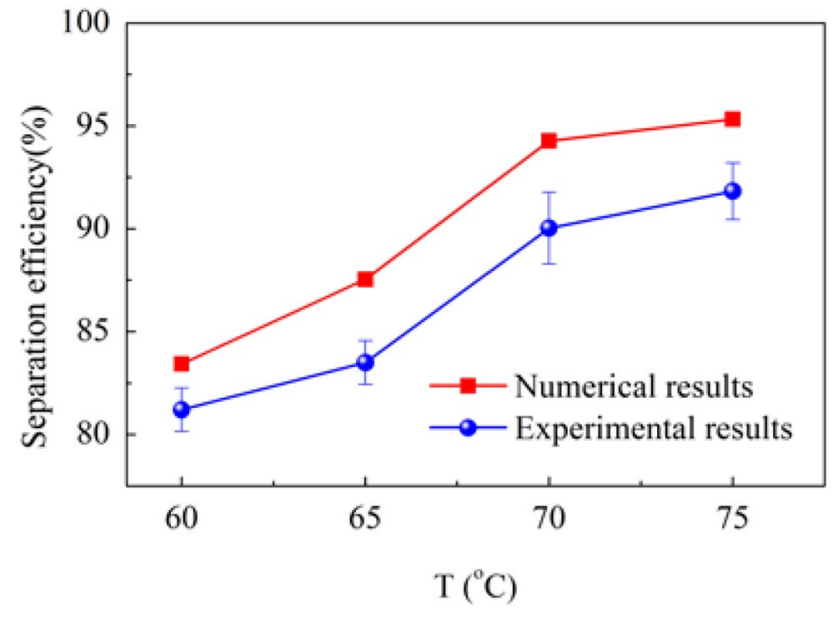

Fig. 7 The double-field coupling unit separation efficiency versus four different emulsion temperatures. The emulsion temperature of $75^{\circ} \mathrm{C}$ has higher efficiency

numerical simulation, the separation efficiency was obtained by selecting the area-weighted average values of variables at the surfaces of overflow orifice and inlet and using the Eq. (5). Figure 7 shows the separation efficiency curves predicted by numerical method compared to the experimental results at different temperatures. The simulated results of separation efficiency are in good agreement with the experimental results. The separation efficiency gradually increases with the increase in temperature. The reason is that the increase in temperature reduces the viscosity of the continuous phase and it influences the drainage of the thin film between the water droplets to reduce the drainage time and the water droplets coalesces easily in relatively low viscosity oil $[39,40]$. Furthermore, as the temperature increases, the interfacial tension is also reduced to promote coalescence [41]. When the emulsion temperature is $75^{\circ} \mathrm{C}$, the separation efficiency is best. In particular, when the temperature is
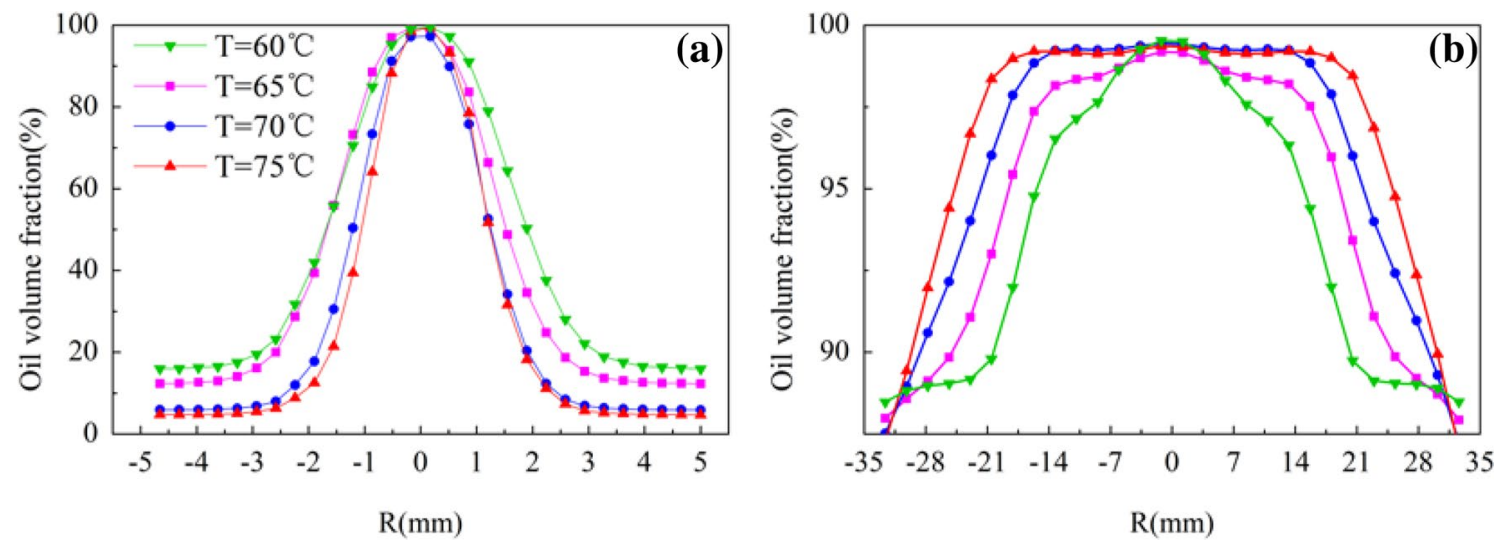

Fig. 6 Radial distribution of oil volume fraction for four different emulsion temperatures at two sections: $\mathbf{a} z=100 \mathrm{~mm}$; b $z=790 \mathrm{~mm}$. Green line + symbol: $60^{\circ} \mathrm{c}$, magenta line + symbol: $65^{\circ} \mathrm{c}$, blue line + symbol: $70^{\circ} \mathrm{c}$, red line + symbol: $75^{\circ} \mathrm{C}$ 
raised from 60 to $65{ }^{\circ} \mathrm{C}$, and from 65 to $70{ }^{\circ} \mathrm{C}$, the separation efficiency increases by approximately $4.1 \%$ and $6.7 \%$, respectively. Gong et al. [42] studied the effects of inlet velocity and voltage amplitude on the separation efficiency of the double-field coupling device and found that the device has a greatly separation performance at $11 \mathrm{kV}$ and $8 \mathrm{~m} / \mathrm{s}$. Therefore, changing the heating temperatures can be the other valuable method for improving the separation performance of coupling device.

\section{Conclusions}

In this study, the effects of different heating temperatures $\left(60{ }^{\circ} \mathrm{C}, 65^{\circ} \mathrm{C}, 70{ }^{\circ} \mathrm{C}\right.$, and $\left.75{ }^{\circ} \mathrm{C}\right)$ in the heat-strengthening process on the separation efficiency of two fields were investigated by numerical simulation and experimental methods. A user-defined function method was used to couple the flow field control equations with the electric field control equations to achieve the coupling simulation of the doublefield coupling device. The liquid-liquid two-phase flow in a double-field coupled device was simulated transiently using a Mixture model and an RSM turbulence model. The results show that the separation efficiency predicted by numerical simulation is in good agreement with the experimental results. And the increase in heating temperature can effectively enhance the separation effect of two fields and improve the efficiency of the oil-water separation of industrial waste oil.

Acknowledgements This work was partially supported by grants from the Chinese National Natural Science Foundation (Grant no. 21676037 and no. 11602045), CQ CSTC projects (Grant no. cstc2017shmsA90009 and Grant no. cstc2015shmszx 90002).

Open Access This article is distributed under the terms of the Creative Commons Attribution 4.0 International License (http://creativeco mmons.org/licenses/by/4.0/), which permits unrestricted use, distribution, and reproduction in any medium, provided you give appropriate credit to the original author(s) and the source, provide a link to the Creative Commons license, and indicate if changes were made.

\section{References}

1. Praporgescu G, Mihalescu S (2011) Study the environmental impact of lubricants used in mechanical systems. Ann Univ Petroşani Mech Eng 13:131-136

2. Su SL, Liew RK, Jusoh A, Cheng TC, Ani FN, Chase HA (2016) Progress in waste oil to sustainable energy, with emphasis on pyrolysis techniques. Renew Sustain Energy Rev 53:741-753

3. Yi H, Zhong CH, Zhang WD, Xiang SU, Wang XX (2015) Research status and prospects of waste lubricating oil combined technology. Mod Chem Ind 35:19-22
4. Rincon J, Canizares P, Garcia MT (2005) Regeneration of used lubricant oil by polar solvent extraction. Ind Eng Chem Res 44:4373-4379

5. Gu G, Liu G, Chen B, Tian M, Wu HY (2015) Research progress of physical demulsification technologies and equipment about W/O emulsions. Chem Ind Eng Prog 34:319-324

6. Gong H, Zhang X, Peng Y, Shang HH, Wang JS (2016) Threefield coupled procedure and equipment for demulsification and dehydration of waste oil. Mod Chem Ind 36:164-167

7. Pan S, Zhang X, Wu F (2010) The study of demulsification in oil water emulsion. J Chongqing Technol Bus Univ (Nat Sci Ed) 27:158-163

8. Eow JS, Ghadiri M, Sharif AO, Williams TJ (2001) Electrostatic enhancement of coalescence of water droplets in oil: a review of the current understanding. Chem Eng J 85:357-368

9. Bailes PJ (1992) Electrically augmented settlers and coalescers for solvent extraction. Hydrometallurgy 30:417-430

10. Eow JS, Ghadiri M (2001) Electro-mechanical coalescer-separators for the separation of aqueous-in-oil dispersions, UK Patent GB 2377397A, publ. date January 15, 2001

11. Eow JS, Ghadiri M (2002) Electrocoalesce-separators for the separation of aqueous drops from a flowing dielectric viscous liquid. Sep Purif Technol 29:63-77

12. Yang X (2009) Drop dynamic of W/O emulsion under the combination of centrifugal field and pulsed electric field. China University of Petroleum, Beijing

13. Wang J (2009) Study of the rule of emulsion's concentration and sedimentation under the combination of high frequency-pulse electric and centrifugal fields. China University of Petroleum, Beijing

14. Li Q, Chen J, Meng L, Pan Z, Wang K (2014) Investigation of water separation from water-in-oil emulsion using high frequency pulsed AC electric field by new equipment. J Dispers Sci Technol 36:918-923

15. Mhatre S, Vivacqua V, Ghadiri M, Abdullah AM, Al-Marri MJ, Hassanpour A, Hewakandamby B, Azzopardi B, Kermani B (2015) Electrostatic phase separation: a review. Chem Eng Res Des 96:177-195

16. Zolfaghari R, Fakhru'L-Razi A, Abdullah LC, Elnashaie SSEH, Pendashteh A (2016) Demulsification techniques of water-inoil and oil-in-water emulsions in petroleum industry. Sep Purif Technol 170:377-407

17. Sun L (2009) Study of the rule of emulsion's concentration and sedimentation under the combination of high frequency-pulse electric and centrifugal fields. China University of Petroleum, Beijing

18. Zhang Y, Liu Y, Ji R, Wang F, Cai B, Li H (2011) Application of variable frequency technique on electrical dehydration of water-in-oil emulsion. Colloids Surf A 386:185-190

19. Cao Y, Jin Y, Li J, Zou D, Chen X (2016) Demulsification of the phosphoric acid-tributyl phosphate (W/O) emulsion by hydrocyclone. Sep Purif Technol 158:387-395

20. Eow JS, Ghadiri M, Sharif AO (2002) Electrostatic and hydrodynamic separation of aqueous drops in a flowing viscous oil. Chem Eng Process 41:649-657

21. Eow JS, Ghadiri M, Sharif AO (2007) Electro-hydrodynamic separation of aqueous drops from flowing viscous oil. J Pet Sci Eng 55:146-155

22. Yang D, Xu M, He L, Luo X, Lu Y, Yan H, Tian C (2015) The influence and optimisation of electrical parameters for enhanced coalescence under pulsed DC electric field in a cylindrical electrostatic coalescer. Chem Eng Sci 138:71-85

23. Murthy YR, Bhaskar KU (2012) Parametric CFD studies on hydrocyclone. Powder Technol 230:36-47

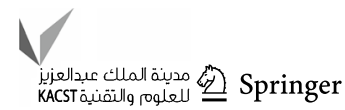


24. Ahmed MA, Nadia GK, Mahmoud RN (2011) Functions of demulsifiers in the petroleum industry. Sep Sci Technol 46:1144-1163

25. Hosseini M, Shahavi MH (2012) Electrostatic enhancement of coalescence of oil droplets (in nanometer scale) in water emulsion. Chin J Chem Eng 20:654-658

26. Kwon WT, Park K, Han SD, Yoon SM, Kim JY, Bae W, Rhee YW (2010) Investigation of water separation from water-in-oil emulsion using electric field. J Ind Eng Chem 16:684-687

27. Zhang Y (2012) Dehydration efficiency of water-in-model oil emulsions in high frequency pulsed DC electrical field: effect of physical and chemical properties of the emulsions. J Dispers Sci Technol 33:1574-1581

28. Peng Y, Liu T, Gong H, Wang J, Zhang X (2015) Effect of pulsed electric field with variable frequency on coalescence of drops in oil. RSC Adv 5:31318-31323

29. Mousavichoubeh M, Ghadiri M, Shariaty-Niassar M (2011) Electro-coalescence of an aqueous droplet at an oil-water interface. Chem Eng Process 50:338-344

30. Motin A (2015) Theoretical and numerical study of swirling flow separation device for oil-water mixtures. Michigan State University, East Lansing

31. Schutz S, Gorbach G, Piesche M (2009) Modeling fluid behavior and droplet interactions during liquid-liquid separation hydrocyclones. Chem Eng Sci 64:3935-3952

32. Tian J, Ni L, Song T, Olson J, Zhao J (2018) An overview of operating parameters and conditions in hydrocyclones for enhanced separations. Sep Purif Technol 206:268-285

33. Peng Y, Liu T, Gong H, Zhang XM (2016) Dehydration of waste lubricating oil by three fields: swirl centrifugal field, pulse electric field and vacuum temperature field. Appl Petrochem Res 6:389-395
34. Huang X (1995) The method of Maxwell stress tensor and its application. J Nanjing Norm Univ 14:41-43

35. Atten P (1993) Electro-coalescence of water droplets in an insulating liquid. J Electrost 30:259-270

36. Fluent AN (2013) ANSYS fluent theory guide. ANSYS Inc, Canonsburg

37. Fluent AN (2013) ANSYS fluent UDF manual. ANSYS Inc, Canonsburg

38. Noroozi S, Hashemabadi SH (2011) CFD analysis of inlet chamber body profile effects on de-oiling hydrocyclone efficiency. Chem Eng Res Des 89:968-977

39. Ata S, Pugh RJ, Jameson GJ (2011) The influence of interfacial ageing and temperature on the coalescence of oil droplets in water. Colloids Surf A 374:96-101

40. Li Y, Gong H, Dong M, Liu Y (2016) Separation of water-inheavy oil emulsions using porous particles in a coalescence column. Sep Sci Technol 166:148-156

41. Binner ER, Robinson JP, Silvester SA, Kingman SW, Lester EH (2014) Investigation into the mechanisms by which microwave heating enhances separation of water-in-oil emulsions. Fuel 116:516-521

42. Gong H, Yu B, Dai F, Peng Y, Shao J (2018) Simulation on performance of a demulsification and dewatering device with coupling double fields: swirl centrifugal field and high-voltage electric field. Sep Purif Technol 207:124-132

Publisher's Note Springer Nature remains neutral with regard to jurisdictional claims in published maps and institutional affiliations. 